\title{
Assessment of Thromboembolism After the Cox-Maze Procedure for Chronic Atrial Fibrillation Secondary to Mitral Valve Lesion
}

\author{
Renato A. K. Kalil, Paula L. M. Nesralla, Gustavo G. Lima, Tiago L. Leiria, Rogério Abrahão, \\ Paulo Moreno, Paulo R. Prates, João R. M. Sant'Anna, Ivo A. Nesralla
}

Porto Alegre, RS - Brazil

\begin{abstract}
Objective - To assess the occurrence of late thromboembolism after surgical repair of chronic atrial fibrillation $(A F)$ simultaneously with repair of mitral valve using the Cox-Maze procedure.
\end{abstract}

Methods - 69 patients underwent Cox 3 procedure, with no cryoablation simultaneously with mitral valvuloplasty or prosthesis. Mean age was $49.9 \pm 13.2$ years. Mean follow-up was of $31.7 \pm 19$ months. Types oflesion were as follows: 33 (48\%) stenoses, 23 (33\%) insufficiencies, and 13 (19\%) double lesions. Procedures were: 64 (93\%) valvuloplasties, 3 (4\%) biological and $2(3 \%)$ mechanical prosthesis placement. There were 9 (13\%) patients with previous systemic embolism and 2 (3\%) had left atrial thrombi.

Results -Early mortality was $7 \%$ and late 1\%. 2 patients (3\%) were reoperated for mitral placement. At last evaluation, 10 patients (15\%), were in AF. The remaining $59(85 \%)$ were either in sinus / atrial rythm (74\%) orunder pacing (12\%). There were no occurrence of early or late, systemic or pulmonary embolism. Permanent anticoagulation was employed in 16 cases, 10 in regular rythm and 6 in $A F$. The remaining 47 (75\%), 2 in AF and 45 in regular rythm, did not receive anticoagulants.

Conclusions - These results are in accordance with others series, where the occurrence of embolism was rare after maze procedure. Permanent systemic anticoagulation seems to be unnecessary in those cases.

Keywords atrial fibrillation, thromboembolism, mitral valve surgery.

Instituto de Cardiologia do Rio Grande do Sul/Fundação Universitária de Cardiologia

Mailing address: - Renato A. K. Kalil - Unidade de Pesquisa do IC/FUC Av.Princesa Isabel, 395-90620-001 - Porto Alegre,RS-E-mail: pesquisa@ cardnet.tche.br English version by Stela Maris C. e Gandour
Atrial fibrillation is the most common arrhythmia. In the general population, its prevalence ranges from $0.15 \%$ to $1 \%$ and progressively increases with age; between the age of 25 and 35 years, the prevalence of atrial fibrillation may reach $0.2 \%$ to $0.3 \%$ of the adult population, and between the age of 55 and 64 years, it may reach 3 to $4 \%$. In individuals above the age of 62 years, the prevalence of this arrhythmia may reach $5 \%$ to $9 \%{ }^{1}$. Atrial fibrillation affects $8.8 \%$ of the individuals older than 80 years and, approximately, $40 \%$ of patients with rheumatic cardiac disease ${ }^{1}$.

Atrial fibrillation is a common complication of several heart diseases, but it has a tendency to develop in specific conditions, of which mitral valve disease is the most common ${ }^{2}$. Approximately $40 \%$ of patients with mitral stenosis and $75 \%$ of those with mitral regurgitation develop atrial fibrillation ${ }^{3}$, which is an arrhythmia accounting for $45 \%$ to $85 \%$ of systemic thromboembolism. The brain is the most frequently affected organ, being involved in more than $2 / 3$ of the thromboembolic events; pulmonary thromboembolism is far less frequent ${ }^{3}$.

Treatment of atrial fibrillation associated with anticoagulation aims to regain sinus rhythm or the control of ventricular frequency. For this, in addition to pharmacological methods, interventional catheterization, implantable defibrillators, and surgery have been used. The Maze technique proposed by Cox et $\mathrm{al}^{4}$ is the surgical procedure with the best results and has been used in several centers. More recently, the electrical isolation of pulmonary veins has been successfully proposed ${ }^{5}$. Prior to this, Graffigna et al ${ }^{6}$ had already proposed left atrial isolation, a procedure in which the pulmonary veins were equally isolated.

Currently, several centers have performed mitral valve surgery associated with the Maze procedure and have been successful in $85 \%$ to $98 \%$ of the cases, in which reversion to atrial rhythm has been obtained ${ }^{7-9}$. Most patients undergoing mitral valve surgery and who have chronic atrial fibrillation do not revert to sinus rhythm with 
the conventional postoperative treatment ${ }^{3}$. Jatene et al ${ }^{10}$ reported in their study that $76.5 \%$ of the patients continued to have atrial fibrillation after surgical repair of the mitral lesion when this was not associated with the Maze procedure. These findings are in accordance with that of previous studies at our institution ${ }^{11}$.

According to the report by Cox et al ${ }^{12}$ in 1999 , the technique may eliminate the risk of thromboembolic phenomena associated with atrial fibrillation. Kosakai ${ }^{13}$, during a 7-year period, did not observe any cases of thromboembolism in patients who obtained reversion to sinus rhythm after the Cox procedure without placement of the valve prosthesis. On the other hand, in 400 patients undergoing the conventional technique with no valve prosthesis placement, $13(3.25 \%)$ episodes of thromboembolism occurred. In Brazil, Jatene et a ${ }^{10}$ observed no thromboembolic phenomenon in the postoperative period of a group of 20 patients, all of whom had undergone the Maze procedure. On the other hand, thromboembolism occurred in $20 \%$ of the 35 patients in the control group, who had undergone only valvar replacement.

With a 7-year experience with the Maze procedure ${ }^{14,15}$,we found it worth assessing the prevalence of late thromboembolism in this series of patients at our institution, correlating it with morbidity, heart rate, and the use of anticoagulant drugs. We also assessed the occurrence of thromboembolism in the postoperative period of the modified Cox 3 procedure for atrial fibrillation secondary to mitral valve disease.

\section{Methods}

We carried out a retrospective review of the medical records and follow-up of 69 patients who had undergone the modified Cox 3 procedure for repair of atrial fibrillation and mitral valvuloplasty or mitral prosthesis placement, from January 1993 to July 1999 at the Instituto de Cardiologia do RS/Fundação Universitária de Cardiologia. The technical modification consisted of not using cryoablation, but more extensive dissection and electrocauterization.

The following parameters were analyzed: the patients' age, sex, valvar lesion, surgery performed (prosthesis or valvuloplasty), follow-up length, associated diseases, use of anticoagulation, complications or sequelae of embolism.

The mean age was $49.9 \pm 13.2$ (20 to 77 ) years. The postoperative follow-up length ranged from 1 to 66 (mean of $31.7 \pm 19)$ months. Twenty-one (30.4\%) patients were males and 48 were females $(69.6 \%)$. The types of lesion were as follows: $33(47.8 \%)$ mitral stenoses, $23(33.3 \%)$ mitral insufficiencies, and 13 (18.8\%) mitral double lesions (fig. 1). The surgeries performed were as follows: 64 (92.8\%) valvuloplasties, 3 (4.3\%) biological prosthesis placements, 2 (2.9\%) mechanical prosthesis placements (fig. 2). In regard to thromboembolic events, $13 \%$ of patients (9) had had systemic embolisms prior to surgery as follows: 1 patient developed upper limb hemiparesis and left palpebral ptosis as a sequela; another patient developed dyslalia and weakness in the right lower limb; and another patient developed paresthesia in the right side of the face and in the left thumb. The $4^{\text {th }}$ patient had dysphasia due to 2 episodes of cerebral em-

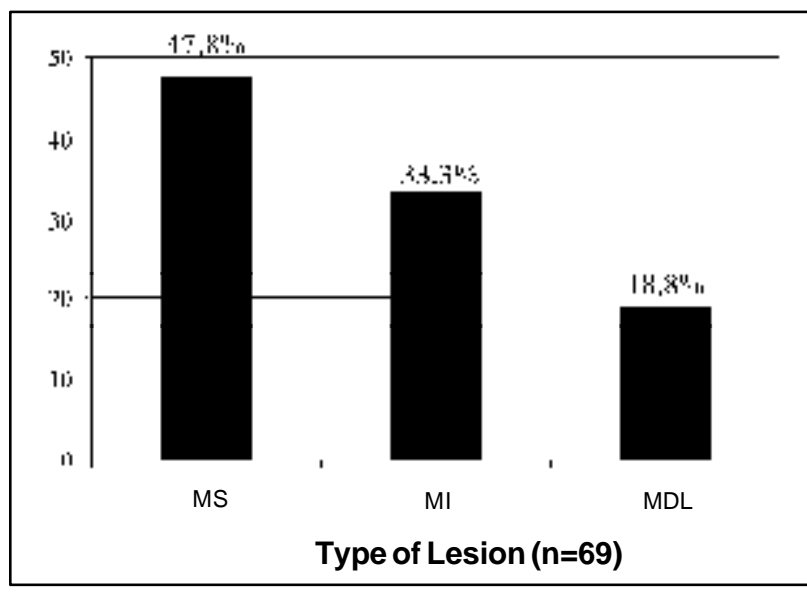

Fig. 1 - Mitral valvopathies classified according to predominance of the lesion. MS= mitral stenosis $; \mathrm{MI}=$ mitral insufficiency $; \mathrm{MDL}=$ mitral double lesion.

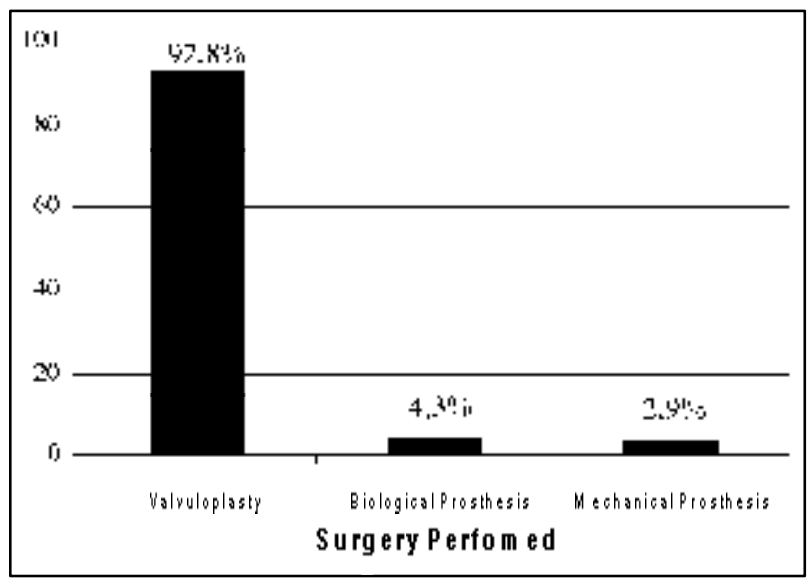

Fig. 2-Type of surgery perfomed.

bolism. The remaining 5 patients had no sequelae. Two (2.9\%) patients had left atrial thrombi detected on echocardiography (fig. 3). Our case series is shown in table I.

Sixteen patients received permanent postoperative anticoagulation, 6 of whom with atrial fibrillation and 10 with regular rhythm. The remaining 47 (74.6\%) patients, 2 with atrial fibrillation and 45 with regular rhythm, did not undergo anticoagulation therapy (tab. I). The surgical staff did not recommend permanent postoperative anticoagulation because of previous atrial fibrillation. However, these $16 \mathrm{pa}-$ tients underwent anticoagulation either because of the presence of the prosthesis, or persistence of atrial fibrillation, or due to precaution, depending on the attending physicians.

\section{Results}

The immediate mortality rate was $7.25 \%$ (5 patients), and the late mortality rate was $1.45 \%$ ( 1 patient) (tab. II and fig. 4). The late death resulted from pulmonary embolism followed by encephalopathy, after acute renal failure, which evolved to death due to multisystem organ failure in the $2^{\text {nd }}$ postoperative month. Two (2.9\%) patients were reoperated upon due to mitral lesion, as recurrence of mitralinsufficien- 


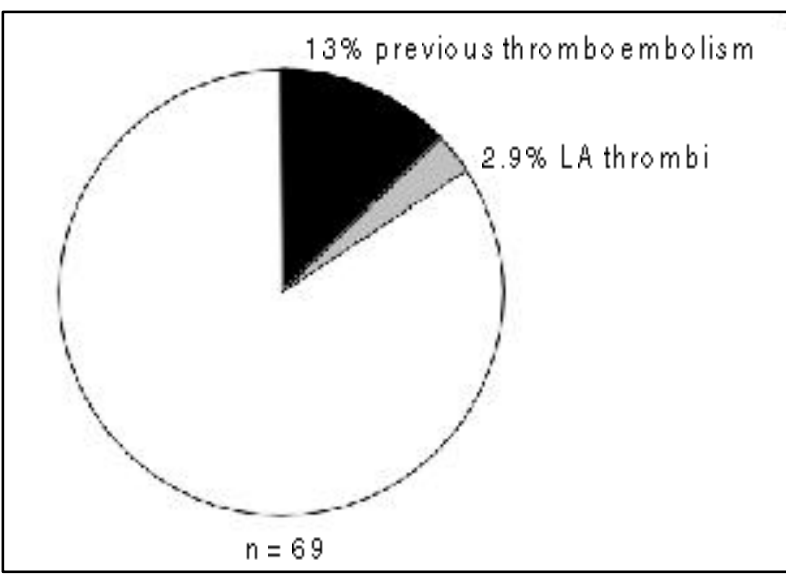

Fig. 3 -Preoperative thrombosis. LA = left atrium.

\begin{tabular}{|lccc|}
\hline \multicolumn{3}{|c|}{ Table I - Case series (N = 69, January 1993 to July 1999) } \\
\hline & & $\mathrm{n}$ & $\%$ \\
\hline \multirow{2}{*}{ Age (years) } & & $49.9 \pm 13.2(20$ to 77$)$ & - \\
Sex & Male & 21 & 30.4 \\
& Female & 48 & 69.6 \\
Lesion & Mitral stenosis & 33 & 47.8 \\
& Mitral insufficiency & 23 & 33.3 \\
& Mitral double lesion & 13 & 18.8 \\
Surgery & Valvuloplasty & 64 & 92.8 \\
& Biological prosthesis & 3 & 4.3 \\
& Mechanical prosthesis & 2 & 2.9 \\
Previous thromboembolism & 9 & 13 \\
Left atrial thrombi & 2 & 2.9 \\
Follow-up (months) & $31.7 \pm 19$ & - \\
\hline
\end{tabular}

cy due to valvuloplasty failure, in the $10^{\text {th }}$ and $59^{\text {th }}$ postoperative months (tab. II). In regard to the current rhythm, $50 \mathrm{pa}-$ tients $(73.5 \%)$ had sinus-atrial rhythm. At the time of the last clinical assessment, $10(14.7 \%)$ patients had atrial fibrillation and 8 patients $(11.8 \%)$ had atrioventricular pacemaker rhythm (tab. III and fig. 5).

A perioperative neurological lesion occurred and was followed by sepsis and death. No late systemic thromboembolism was observed (tab. II).

\section{Discussion}

Atrial fibrillation is, in clinical practice, the most common sustained arrhythmia. Its presence almost doubles mortality and increases the risk of cerebral stroke 5 times, as compared with the mortality of the population without the arrhythmia. In patients with rheumatic mitral stenosis, the increase in the risk of cerebral stroke may reach 18 times $^{1}$.

The major objective of our study was to assess the occurrence of late thromboembolism after the modified Cox 3 procedure, and to correlate it with clinical results and the permanent use of anticoagulation.

In regard to conversion to sinus or atrial rhythm, we found several reports in the literature, such as the study by Kim et al ${ }^{16}$, who reported a conversion rate to sinus rhythm

\begin{tabular}{|lcc|}
\hline \multicolumn{2}{|c|}{ Table II - Immediate and late morbidity and mortality } \\
\hline Events & $\mathrm{N}$ & $\%$ \\
\hline Reoperations & 2 & 2.9 \\
Late thromboembolism & 0 & 0 \\
Immediate mortality & 5 & 7.25 \\
Late mortality & 1 & 1.45 \\
\hline
\end{tabular}

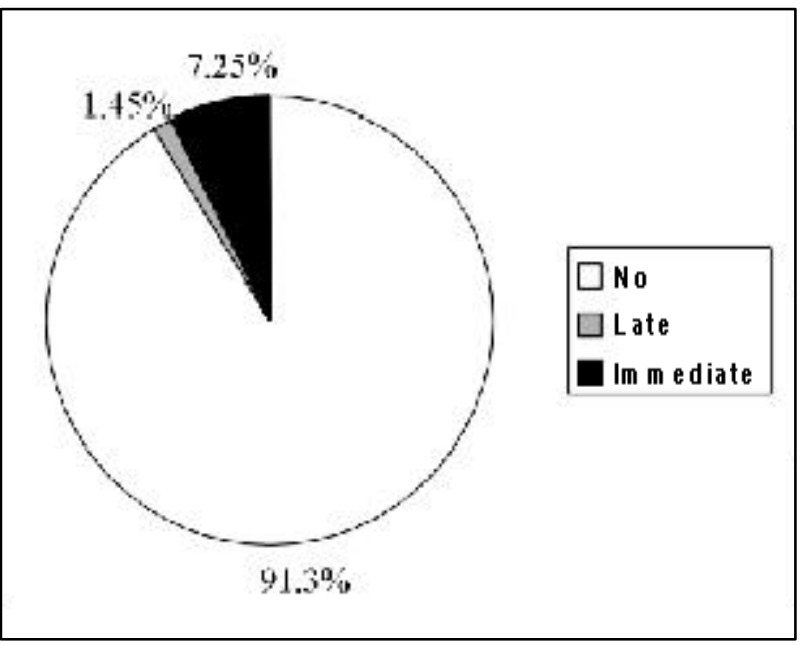

Fig. 4-Immediate and late mortality.

\begin{tabular}{|lcc|}
\hline \multicolumn{2}{|c|}{ Table III - Postoperative rhythm at the time of the last evaluation } \\
\hline Rhythm & Patients $(\mathrm{N}=68)$ & $\%$ \\
\hline Sinus/atrial & 50 & 73.5 \\
Atrial fibrillation & 10 & 14.7 \\
Pacemaker & 8 & 11.8 \\
\hline
\end{tabular}

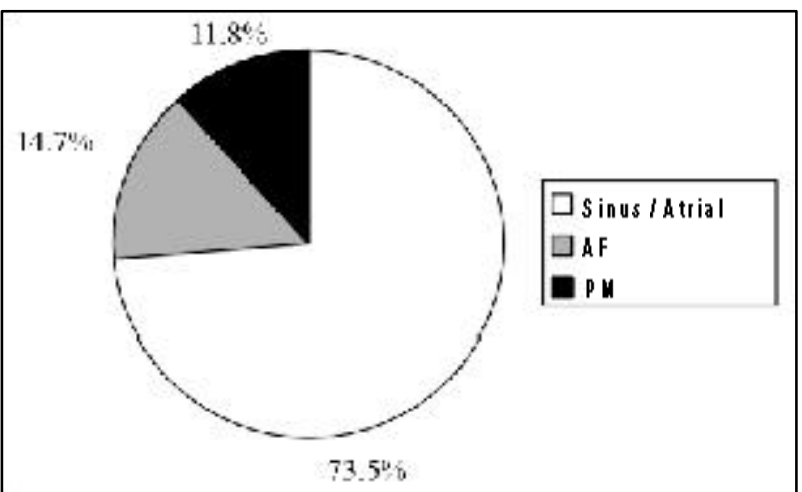

Fig. 5 - Postoperative rhythm in the last evaluation. AF = atrial fibrillation; $\mathrm{PM}=$ pacemaker

of $81 \%$ in patients who had undergone the Cox-Maze 3 procedure. Jatene et $\mathrm{al}^{10}$, in their study evaluating cardiac rhythm in a series of 20 patients, observed reversion of atrial fibrillation to regular rhythm in all patients. Of these 20 patients, $75 \%$ had sinus rhythm and 25\% had junctional rhythm. McCarthy et al ${ }^{17}$ reported a reversion to sinusrhythm of $100 \%$ during 
ambulatory follow-up of at least 3 months. Our results show that $73.5 \%$ of patients had sinus-atrial rhythm at their last ambulatory visit, and $11.8 \%$ had atrioventricular pacemaker rhythm with consequent atrial contraction, resulting in $85.3 \%$ of atrial fibrillation reversion.

Cox et al ${ }^{12}$, in a series of 306 patients, reported a mortality of $3.3 \%$ in the immediate postoperative period and 1 intraoperative death. On the other hand, Kim et al ${ }^{16}$ reported no deaths in their series of 32 patients. The same occurred with Kosakai et $\mathrm{al}^{18}$, who reported no deaths in the immediate and late postoperative period. McCarthy et al ${ }^{17}$ reported a $7 \%$ mortality in the immediate postoperative period. Chua et a ${ }^{19}$ reported an immediate postoperative mortality of approximately $2.5 \%$. We observed a $7.2 \%$ immediate mortality and a $1.4 \%$ late mortality.

Cox et al ${ }^{12}$ reported $2(0.7 \%)$ patients with thromboembolic events during surgery, and, in 265 patients followed up for more than 11.5 years, 1 patient with thromboembolism with no sequelae. Jatene et al ${ }^{10}$ reported no case of thromboembolism. Kosakai et al ${ }^{18}$, in a series of 62 patients, reported 1 episode of transient neurological ischemia in the late postoperative period. McCarthy et al ${ }^{17}$ reported embolic events in 3 out of their 14 patients, who underwent only the Cox-Maze procedure. Chua et al ${ }^{19}$ reported a $3.6 \%$-incidence of thromboembolism in their series. In our study, we observed no late episodes of thromboembolism.

On the other hand, in regard to preoperative events, 58 (18.9\%) patients in the series of Cox et al ${ }^{12}$ had a history of thromboembolism prior to surgery. In our study, 9(13\%) patients had previous episodes of thromboembolism.

In patients undergoing the Cox-Maze procedure, the permanent use of anticoagulation has been the object of discussion. Usually, anticoagulation is decided by the attending physician, even though surgeons do not recommend it as a routine measure.

In our series, 16 patients underwent anticoagulation. Kosakai et al ${ }^{18}$ suspended the use of anticoagulation in $67 \%$ of their patients after surgical repair, corresponding to those who reverted to atrial rhythm. Cox et al ${ }^{12}$ used anticoagulation in all patients with a mechanical prosthesis, who accounted for $40 \%$ of their sample. Chua et al ${ }^{19}$ performed systemic anticoagulation in all their patients during the first 6 postoperative weeks, and this therapy was maintained in the patients who persisted with arrhythmia. These authors also reported that determining the risk of late thromboembolism according to the use of anticoagulant drugs was not possible. They concluded that repair of the mitral valve lesion through valvuloplasty increases conversion to sinus rhythm in the postoperative period and reduces the need for anticoagulation.

In conclusion, in our series, the Maze procedure was effective in establishing sinus rhythm or, at least, atrial rhythm, preserving the function of atrial transportation. During the period studied, no systemic thromboembolic episode occurred in the patients undergoing anticoagulation and in the majority of those not undergoing anticoagulation. Even though, we did not have a control group in our series, the occurrence of thromboembolism was lower than that expected according to data in the literature. Our experience allows us to infer that the Cox-Maze procedure may effectively prevent late thromboembolism after mitral valve repair in patients with previous chronic atrial fibrillation.

\section{References}

1. Lima GG, Medeiros CM, Dubuc M. Fibrilação Atrial. In: Castro I, Cantarelli E, Ramres JAF, Luna RL, Feitosa GS. Cardiologia, Princípios e Prática. Porto Alegre: Artes Médicas Sul Ltda, 1999; 35: 584-90.

2. Lie JT, Falk R, James T. Atrial Fibrilation: Mechanism and Management. $2^{\text {nd }}$ ed. Philadelphia: Lippincott-Raven Publishers, 1997.

3. Murgatroyd FD, Camm AJ. Atrial Fibrilation for The Clinician. Vol. 4. Armonk: Futura, 1995: 140p.

4. Cox JL, Schuessler RB, Dagostino HJ. The Surgical treatment of atrial fibrillation, III. Development of a definitive surgical procedure. J Thorac Cardiovasc Surg 1991;101:569-83.

5. Sueda T, Nagata H, Orihashi K, et al. Efficacy of a simple left atrial procedure for chronic atrial fibrillation in mitral valve. Ann Thorac Surg 1997; 63: 1070-5.

6. Graffigna A, Pagani F, Minzioni G, Salermo J, Vigano M. Left atrial isolation associated with mitral valve operations. Ann Thorac Surg 1992; 54: 1093-8.

7. Melo JQ, Neves JP, Abecasis LM, Adragão P, Ribeiras R, Seabra-Gomes R. Operative risks of the Maze procedure associated with mitral valve surgery. Cardiovasc Surg 1997; 5: 112-6.

8. Sandoval N, Velasco VM, Orjuela H, et al. Concomitant mitral valve or atrial septal defect surgery and the modified Cox-Maze procedure. Am J Cardiol 1996; 77:591-6.

9. Handa N, Schaff HV, Morris JJ, Anderson BJ, Kopecky SL, Enriquez-Sarano M. Outcome of valve repair and the Cox Maze procedure for mitral regurgitation and associated atrial fibrillation. J Thorac Cardiovasc Surg 1999; 118: 628-35.
10. Jatene MB, Marcial MB, Tarasoutchi F, Cardoso RA, Pomerantzeff PMA, Jatene AD. Influência da operação de Cox no tratamento da fibrilação atrial em valvuloplastia mitral reumática: análise comparativa de resultados imediatos e tardios. Rev Bras Cir Cardiovasc 1998; 13: 105-19.

11. KalilRAK, MaratiaCB,D'Ávila A, Ludwig FB. Predictive factors for persistence of atrial fibrillation after mitral valve operation. Ann Thorac Surg 1999; 67: 614-7.

12. Cox JL, Ad N, Palazzo T. Impact of Maze procedure on the stroke rate in patients with atrial fibrilation. J Thorac Cardiovasc Surg 1999; 118: 833-40.

13. Kosakai Y. Maze results in Tarazuka City Hospital. In: Web: http://www.ctsnet. org/forum/81/0/2292, Apr, 1999, on Internet.

14. Kalil AK, Albrecht A, Lima G, et al. Resultados do tratamento cirúrgico da fibrilação atrial crônica. Arq Bras Cardiol 1999; 73: 139-43.

15. Kalil RAK. Tratamento cirúrgico da fibrilação atrial. Rev AMRIGS 1998; 42: 125-31.

16. Kim YJ, Shohn D, Park D, et al. Restoration of atrial mechanical function after Maze operation in patients with structural heart disease. Am Heart J 1998; 136: 1070-4

17. McCarthy PM, Castle LW, Maloney JD, et al. Initial experience with the Maze procedure for atrial fibrilation. J Thorac Cardiovasc Surg 1993; 105: 1077-87.

18. Kosakai Y, Kawaguchi AT, Isobe F, et al. Cox Maze procedure for chronic atrial fibrilation associated with mitral valve disease. J Thorac Cardiovasc Surg 1994; 108: 1049-55

19. Chua YL, SchaffHV, Orszulak TA, Morris JJ. Outcome of mitral valve repair in patients with preoperative atrial fibrilation. J Cardiovasc Surg 1994; 107: 408-15. 